\title{
International medical graduates in family medicine in the United States of America: an exploration of professional characteristics and attitudes
}

\author{
Amanda L Morris*1, Robert L Phillips², George E Fryer Jr², Larry A Green² and \\ Fitzhugh Mullan 4
}

Address: ${ }^{1}$ Sigma Medical Group, West Lafayette, Indiana, USA, ${ }^{2}$ Robert Graham Center Policy Studies in Family Medicine and Primary Care, Washington, DC, USA, ${ }^{3}$ Department of Pediatrics, New York University, New York City, USA and ${ }^{4}$ Department of Health Policy, George Washington University School of Public Health and Health Services, Washington, DC, USA

Email: Amanda L Morris* - amanda@jfmorris.net; Robert L Phillips - bphillips@aafp.org; George E Fryer - fryerg01@med.nyu.edu; Larry A Green - lgreen@aafp.org; Fitzhugh Mullan -fmullan@projecthope.org

* Corresponding author

Published: 18 July 2006

Human Resources for Health 2006, 4:17 doi:10.1186/1478-4491-4-17

This article is available from: http://www.human-resources-health.com/content/4/1/17

(C) 2006 Morris et al; licensee BioMed Central Ltd.

This is an Open Access article distributed under the terms of the Creative Commons Attribution License (http://creativecommons.org/licenses/by/2.0), which permits unrestricted use, distribution, and reproduction in any medium, provided the original work is properly cited.
Received: 09 September 2005

Accepted: 18 July 2006

\begin{abstract}
Background: The number of international medical graduates (IMGs) entering family medicine in the United States of America has steadily increased since 1997. Previous research has examined practice locations of these IMGs and their role in providing care to underserved populations. To our knowledge, research does not exist comparing professional profiles, credentials and attitudes among IMG and United States medical graduate (USMG) family physicians in the United States. The objective of this study is to determine, at the time when a large influx of IMGs into family medicine began, whether differences existed between USMG and IMG family physicians in regard to personal and professional characteristics and attitudes that may have implications for the health care system resulting from the increasing numbers of IMGs in family medicine in the United States.
\end{abstract}

Methods: This is a secondary data analysis of the 1996-1997 Community Tracking Study (CTS) Physician Survey comparing 2360 United States medical graduates and 366 international medical graduates who were nonfederal allopathic or osteopathic family physicians providing direct patient care for at least 20 hours per week.

Results: Compared to USMGs, IMGs were older $(p<0.001)$ and practised in smaller $(p=0.0072)$ and younger practices $(p<0.00 I)$. Significantly more IMGs practised in metropolitan areas versus rural areas $(p=0.0454)$. More IMG practices were open to all new Medicaid $(p=0.018)$ and Medicare $(p=0.045 \mathrm{I})$ patients, and a greater percentage of their revenue was derived from these patients $(p=0.0020$ and $p=$ $0.0310)$. Fewer IMGs were board-certified $(p<0.001)$. More IMGs were dissatisfied with their overall careers $(p=0.0190)$. IMGs and USMGs did not differ in terms of self-rated ability to deliver high-quality care to their patients $(p=0.4626)$. For several of the clinical vignettes, IMGs were more likely to order tests, refer patients to specialists or require office visits than USMGs.

Conclusion: There are significant differences between IMG and USMG family physicians' professional profiles and attitudes. These differences from 1997 merit further exploration and possible follow-up, given the increased proportion of family physicians who are IMGs in the United States. 


\section{Background}

International Medical Graduates (IMGs) comprised $20.8 \%$ of the family physician workforce in 1995 [1]. In 2003 , this number increased to $22.1 \%$ and is expected to continue to rise, given the large increase of IMGs entering family medicine residency programmes [1].

Historically, family medicine has a smaller proportion of IMGs entering residency training than other primary-care specialties. This relationship is changing as IMGs increasingly filled family medicine residency positions not selected by United States Medical Graduates (USMGs), particularly those vacant after the annual Match [2].

In the 2005 Match, $36.5 \%$ of PGY-1 positions available in family medicine residencies were filled by IMGs, an increase of 97 positions from the previous year [3]. On 1 July 2005, IMGs comprised $39.6 \%$ of first-year family medicine residents, compared to $14.7 \%$ in 1998 [3]. This rise is unique to family medicine, as the number of IMGs entering other primary-care fields has remained relatively stable over the past eight years [4].

Earlier research documented that certain residency programmes have become "dependent" on IMGs, who occupy most or all of their positions [2,5]. It is possible that differences in training backgrounds may translate to important differences in the practice of medicine relating to issues such as health care costs and access to care. As the United States relies heavily on family physicians to serve a large portion of its population [6], it is important to consider what, if anything, this influx of IMGs might portend for the future of the specialty and health care in the nation.

IMG's geographical and specialty distributions, their contribution to meeting the needs of the medically underserved, and the value of Conrad-20 and other visa-waiver programmes that integrate them into the United States physician workforce have been examined in past studies [7-10]. A few studies have focused on IMGs performance at the residency training level and their post-training medical practices [11-13]. Although several of these studies evaluate IMGs in primary-care specialties, none of them focus solely on the field of family medicine. Previous research has neither described the attributes and influences of IMG medical practices nor characterized IMGs' professional credentials and attitudes beyond the residency level in family medicine.

In this paper we examine personal, professional and practice characteristics and attitudes of IMG and USMG family physicians in order to provide insight into practice differences that may affect the health care system. We use data from a nationally representative survey collected in 1996-
1997, a time when major increases in the proportion of IMGs in family medicine residency training began, to answer the question: "Do significant differences exist between IMG and USMG family physicians that warrant further investigation?"

We compare physician-reported personal, professional and practice characteristics, attitudes regarding clinical care, assessments of various influences on the delivery of medical care, referral patterns and responses to clinical vignettes between the two groups. Beyond forming a baseline comparison and characterization for future analyses, this analysis highlights findings that may have implications for the health care system as a whole resulting from the increasing numbers of IMGs in family medicine in the United States.

\section{Methods \\ Data sources}

Data used in this study were collected through the Community Tracking Study (CTS) Physician Survey, a project of the Center for Studying Health System Change, in Washington, DC, and obtained from the Inter-University Consortium for Political and Social Research (ICPSR), in Ann Arbor, Michigan [14]. The CTS is a biannual survey sponsored by the Robert Wood Johnson Foundation to study changes in the health care system and their impact on individuals. The sample frame consisted of nonfederal MDs and DOs who provided direct patient care for at least 20 hours per week.

The 1996-1997 CTS is the most recent source of a nationally representative sample containing special provisions to examine practice characteristics and tendencies in addition to the responses to 12 clinical vignettes. Primary-care physicians were oversampled, and of the 2726 family physicians who participated, 2360 were USMGs and 366 were IMGs. Residents and fellows were not surveyed. The overall response rate was $65 \%$ and the response number to each individual item is listed in each table. The CTS does not identify the specific response rates between IMG and USMG participants.

\section{Study variables}

We compared responses to survey items between IMG and USMG family physicians. The CTS defined International Medical Graduates as graduates of medical schools outside the United States, Canada and Puerto Rico. The CTS also included the responses from general practitioners in the family physician group.

We examined several survey items relating to personal and professional characteristics including age, years in practice, net income and board-certification status. We assessed various practice characteristics including practice 
location (large metro, small metro, non-metro as defined by the 1995 United States Census), practice type (solo or two physicians, group practice, health maintenance organization (HMO), hospital-based, medical school, other), net income and percentages of income from various sources (Medicare, Medicaid, HMO, bonuses). We also compared the number of new Medicare and Medicaid patients each physician was accepting into his or her practice.

The survey items queried physicians' agreement with statements regarding clinical care using a five-point Likert scale ("disagree strongly", "disagree somewhat", "neither agree nor disagree"," agree somewhat", or "agree strongly"). There were few "neither agree nor disagree" responses. In order to compare each group, we eliminated the category and collapsed the remaining groups into two response groups: "agree" or "disagree", as has been done with analysis of these data in other research [15].

The physicians were similarly asked about career satisfaction ("Thinking very generally about your overall career in medicine, would you say that you are currently very satisfied, somewhat satisfied, somewhat dissatisfied, very dissatisfied, or neither satisfied or dissatisfied?"). These responses were collapsed to "dissatisfied" or "satisfied" for our analysis.

We compared survey items that assessed various influences on the physicians' practice of medicine. These items include the effects of using computers to obtain patient data and treatment guidelines, using preventive treatment reminders and formal written guidelines, and the effects of practice profile results and patient satisfaction surveys.

In order to compare referral patterns among physicians, we analysed responses to survey items regarding the number of patients the physicians referred to specialists, the complexity of the medical conditions of those patients they did not refer to specialists, and the complexity of medical conditions the physicians felt specialists expected them to care for without referral. These survey items asked each physician to state whether each item had "decreased a lot", "decreased a little", "stayed the same", "increased a little", or "increased a lot" over the previous two years.

The 1996-1997 CTS contained 12 clinical vignettes that queried physicians about medications, tests and referrals they would order for various clinical scenarios.

\section{Analytic strategy}

USMG and IMG practice characteristics, professional attitudes and satisfaction were contrasted by means of chisquare and t-tests. SUDAAN software, version 8.0 (Research Triangle Institute, Research Triangle Park,
North Carolina, United States of America) was used for statistical comparisons and making national estimates. SUDAAN adjusted variance due to non-response and CTS survey design complexities. Statistical significance was set at p-values less than 0.05 .

\section{Results}

Of the 2726 family physicians surveyed, 2360 were USMGs and 366 were IMGs. We found that IMGs were older than USMGs, but significantly more likely to have been in practice for fewer years (Table 1). IMGs were more likely to practise in metropolitan areas than in non-metropolitan areas, with $82 \%$ of IMGs in metropolitan areas compared to $75 \%$ of USMGs ( $\mathrm{p}=0.0454)$. A greater percentage of IMGs were full owners of their practices and more often in solo or two-physician groups. Only $67 \%$ of IMGs were board-certified, compared to $87 \%$ of USMGs $(\mathrm{p}<0.001)$. More IMGs were accepting all new Medicare $(67 \%$ versus $60 \%, p=0.0451)$ and Medicaid $(49 \%$ versus $40 \%, \mathrm{p}=0.0018$ ) patients than USMGs. They also derived a greater percentage of their revenue from Medicare and Medicaid than their USMG counterparts. IMGs served as "gatekeepers" and were required to provide permission to see specialists for a greater percentage of their patients than USMGs. Differences between IMGs and USMGs regarding net income, hours in direct patient care, percentage of revenue from managed care, and percentage of income from bonuses were not significant (data not shown).

IMGs were more likely to report having adequate time to spend with patients $(73 \%$ versus $66 \%, \mathrm{p}=0.0041)$ and being able to develop continuing patient relationships ( $83 \%$ versus $78 \%, p=0.0096)$ than USMGs, yet more IMGs were dissatisfied with their overall medical careers ( $20 \%$ versus $16 \%, \mathrm{p}=0.0190$ ) than USMGs (Table 2 ).

There were no significant differences between IMGs and USMGs regarding perceived ability or freedom to provide high-quality care, to communicate with specialists and to make clinical decisions without reducing income. IMGs reported that preventive treatment reminders, formal written guidelines and patient satisfaction surveys had more influences on their practice of medicine than USMGs (data not shown).

There were no significant differences between IMGs and USMGs on the effects of using computers on obtaining patient data and treatment guidelines and the effects of practice profile results (data not shown). Small but significant differences existed between IMGs and USMGs with regard to referral patterns, but no meaningful trends were identified (data not shown). 
Table I: Personal, professional and practice characteristics of IMG and USMG family physicians

\begin{tabular}{|c|c|c|c|}
\hline & USMGs $\mathrm{N}=2360 \mathrm{n}(\%) *$ & IMGs $N=366 n(\%)^{*}$ & p value ${ }^{* *}$ \\
\hline \multicolumn{4}{|l|}{ Age $(n=2591)$} \\
\hline$<35$ & $299(13)$ & $13(3)$ & $<0.001$ \\
\hline $35-44$ & $949(43)$ & $106(33)$ & \\
\hline $45-54$ & $588(26)$ & 117 (33) & \\
\hline $55-64$ & $251(12)$ & $63(18)$ & \\
\hline$>65$ & $163(7)$ & $42(13)$ & \\
\hline \multicolumn{4}{|l|}{ Years in practice $(n=2726)$} \\
\hline Under 6 & 449 (19) & $81(23)$ & $<0.001$ \\
\hline $6-10$ & $504(22)$ & $51(12)$ & \\
\hline $1 \mathrm{I}-20$ & $830(35)$ & $121(34)$ & \\
\hline $21-30$ & $279(12)$ & $56(15)$ & \\
\hline $31-40$ & $234(10)$ & $43(12)$ & \\
\hline $41+$ & $64(3)$ & $14(4)$ & \\
\hline \multicolumn{4}{|l|}{ Location $(n=2726)$} \\
\hline Large metro $>200 \mathrm{~K}$ & $1955(70)$ & $322(76)$ & 0.0454 \\
\hline Small metro $<200 \mathrm{~K}$ & $45(5)$ & $7(6)$ & \\
\hline Non-metro area & $360(25)$ & $37(18)$ & \\
\hline \multicolumn{4}{|l|}{ Ownership status $(n=2726)$} \\
\hline Full owner & $733(32)$ & $150(43)$ & $<0.001$ \\
\hline Part owner & $472(21)$ & $52(14)$ & \\
\hline Not an owner & $1155(48)$ & $164(43)$ & \\
\hline \multicolumn{4}{|l|}{ Practice type $(n=2726)$} \\
\hline Solo or 2 physicians & $829(37)$ & $169(47)$ & 0.0072 \\
\hline Group $\geq 3$ physicians & $585(24)$ & $76(2 I)$ & \\
\hline Health maintenance organization & $154(5)$ & $27(5)$ & \\
\hline Medical school & $89(4)$ & II (4) & \\
\hline Hospital-based & $388(17)$ & $46(13)$ & \\
\hline Other & $315(13)$ & $37(9)$ & \\
\hline \multicolumn{4}{|c|}{ Board certification status $(n=2707)$} \\
\hline Board Certified & $2055(87)$ & $243(67)$ & $<0.001$ \\
\hline Board Eligible Only***** & $169(7)$ & $61(18)$ & \\
\hline Neither & $123(6)$ & $56(15)$ & \\
\hline \multicolumn{4}{|c|}{ Accepting new Medicare patients $(n=2726)$} \\
\hline None & $222(9)$ & $27(9)$ & $0.045 I$ \\
\hline Some & $418(17)$ & $43(12)$ & \\
\hline Most & $339(14)$ & $51(12)$ & \\
\hline All & $138 \mid(60)$ & $245(67)$ & \\
\hline \multicolumn{4}{|c|}{ Accepting new Medicaid patients $(n=2726)$} \\
\hline None & $647(25)$ & $94(24)$ & 0.0018 \\
\hline Some & $591(25)$ & $67(18)$ & \\
\hline Most & $231(10)$ & $35(9)$ & \\
\hline All & $891(40)$ & $170(49)$ & \\
\hline $\begin{array}{l}\text { Percentage of revenue from } \\
\text { Medicare }(n=2726)\end{array}$ & Mean (SE) 27.54 (0.48) & Mean (SE) 30.62 (I.46) & $0.0310 * * *$ \\
\hline $\begin{array}{l}\text { Percentage of revenue from } \\
\text { Medicaid }(n=2726)\end{array}$ & Mean (SE) I3.90 (0.48) & Mean (SE) I7.82 (I.3I) & $0.0020 * * *$ \\
\hline $\begin{array}{l}\text { Percentage of patients for } \\
\text { whom physician serves as } \\
\text { gatekeeper }(n=2726)\end{array}$ & Mean (SE) 36.72 (0.94) & Mean (SE) 43.67 (2.34) & $0.0018 * * *$ \\
\hline
\end{tabular}

*Unweighted number of survey respondents and weighted percentage of family physicians. Numbers vary because not all survey items were answered by each physician.

** Chi-Square

**** T-Test

*****Although "Board Eligible" is not a status officially recognized by the ABFM, it is one of the responses offered by the CTS.

USMG = United States Medical Graduate, IMG = International Medical Graduate, SE = Standard Error 
Table 2: Attitudes regarding clinical care of IMG and USMG family physicians

\begin{tabular}{|c|c|c|c|}
\hline & USMGs $N=2360 \mathrm{n}(\%)^{*}$ & IMGs $N=366 \mathrm{n}(\%)^{*}$ & p value** \\
\hline \multicolumn{4}{|c|}{ "I have adequate time to spend with my patients during typical office/patient visits." ( $n=2664)$} \\
\hline Disagree & $813(34)$ & $102(27)$ & 0.0041 \\
\hline Agree & $1492(66)$ & $257(73)$ & \\
\hline \multicolumn{4}{|c|}{$\begin{array}{l}\text { "It is possible to maintain the kind of continuing relationships with patients over time that promote the delivery of high quality } \\
\text { care." }(n=265 \mathrm{I})\end{array}$} \\
\hline Disagree & $559(22)$ & $63(17)$ & 0.0096 \\
\hline Agree & $1738(78)$ & $291(83)$ & \\
\hline \multicolumn{4}{|c|}{ "It is possible to provide high-quality care to all my patients." $(n=2679)$} \\
\hline Disagree & $442(19)$ & $73(18)$ & 0.4626 \\
\hline Agree & $1875(81)$ & $289(82)$ & \\
\hline \multicolumn{4}{|c|}{ "I have the freedom to make clinical decisions that meet my patients' needs." $(n=2685)$} \\
\hline Disagree & $332(14)$ & $61(17)$ & 0.1677 \\
\hline Agree & $1991(86)$ & $301(83)$ & \\
\hline \multicolumn{4}{|c|}{$\begin{array}{l}\text { "The level of communication I have with specialists about the patients I refer to them is sufficient to ensure the delivery of a high } \\
\text { quality of care." }(n=2679)\end{array}$} \\
\hline Disagree & $276(11)$ & $46(12)$ & 0.5777 \\
\hline Agree & $2045(89)$ & $312(88)$ & \\
\hline \multicolumn{4}{|c|}{ "I can make clinical decisions in the best interests of my patients without the possibility of reducing my income." ( $n=260 \mathrm{I})$} \\
\hline Disagree & $447(19)$ & $74(21)$ & 0.5571 \\
\hline Agree & $1800(81)$ & $280(79)$ & \\
\hline \multicolumn{4}{|c|}{ Overall career satisfaction $(n=2678)$} \\
\hline Dissatisfied & $382(16)$ & $79(20)$ & 0.0190 \\
\hline Satisfied & $1978(84)$ & $287(80)$ & \\
\hline
\end{tabular}

*Unweighted number of survey respondents and weighted percentage of family physicians. Numbers vary because not all survey items were answered by each physician.

*** T-Test

USMG = United States Medical Graduate, IMG = International Medical Graduate

The responses to the 12 clinical vignettes are listed in Table 3. For many clinical scenarios, IMGs were more likely to order tests, refer patients to specialists or require office visits than USMGs.

\section{Discussion}

This study suggests that IMGs and USMGs who practise family medicine differ in important ways. Professionally, fewer IMGs are board-certified, compared to USMGs. Their practices differ from those of USMGs in terms of practice location and service of the Medicare and Medicaid populations. Significantly fewer IMGs report being satisfied overall with their medical careers than USMGs. Furthermore, subtle differences exist between the groups in regards to patient referral patterns and in their responses to several clinical vignettes. These differences, if they continue to exist, may affect important aspects of the health care system, particularly access to care and health care use and costs.

\section{Fewer IMGs are board-certified than USMGs}

The CTS survey data do not allow us to ascertain the etiology of this profound difference. Prerequisites for becoming board-certified in family medicine include unlimited licensure to practise medicine, completion of a three-year residency programme in family medicine, with the last two years being at the same location, and a passing score on the American Board of Family Practice Board Certification Exam.

Physicians surveyed in this study were practising medicine prior to the implementation of the Clinical Skills Assessment (CSA) requirement for IMGs to enter United States residency programmes. This requirement was implemented by the Educational Commission for Foreign Medical Graduates (ECFMG) in July 1998 to evaluate IMGs' clinical and communication skills [16]. Since the implementation of the CSA, the United States Medical Licensing Exam (USMLE) Step 1 and 2 passage rates of IMGs receiving ECFMG certification have increased. We may also see increases in the percentage of board-certified IMG family physicians in the future with this new requirement.

It is uncertain how board certification and exam-passing rates correlate to quality outcomes in clinical practice. An extensive literature review performed in 1997 revealed that insufficient evidence existed to support or refute the use of board certification as a proxy for physician quality [12]. More recent studies suggest that board certification and maintenance of certification may be linked to improved clinical outcomes [17]. Furthermore, the public places a high value on board certification and would potentially change behaviour to ensure their physician is board-certified[17]. The difference between IMGs' and 
Table 3: Responses to clinical vignettes of IMG and USMG family physicians

\begin{tabular}{|c|c|c|c|}
\hline Clinical vignette & $\begin{array}{l}\text { USMGs } N= \\
2360 \text { Mean (SE) }\end{array}$ & $\begin{array}{l}\text { IMGs } N=366 \\
\text { Mean (SE) }\end{array}$ & p value* \\
\hline $\begin{array}{l}\% 50 \text { y/o males prescribed oral agents for total cholesterol of } 240 \text {, LDL of I } 50 \text { and HDL of } 50 \\
\text { after } 6 \text { months of diet therapy and no other cardiac risk factors }(n=2726)\end{array}$ & $21.60(0.87)$ & $22.92(1.71)$ & 0.4533 \\
\hline $\begin{array}{l}\% 60 \text { y/o males referred to urology for moderate BPH symptoms without signs of renal } \\
\text { disease or cancer }(n=2726)\end{array}$ & $11.65(0.55)$ & $15.52(1.77)$ & 0.0276 \\
\hline $\begin{array}{l}\% 50 \text { y/o males with I month history of exertional chest pain referred to Cardiology after an } \\
\text { abnormal stress test }(n=2726)\end{array}$ & $47.20(1.15)$ & $50.93(2.80)$ & 0.1791 \\
\hline$\% 35$ y/o males ordered MRI for acute low back pain with new left foot drop $(n=2726)$ & $33.39(0.90)$ & $39.58(1.97)$ & 0.0036 \\
\hline $\begin{array}{l}\text { \% Asymptomatic, male, Caucasian patients }>60 \text { y/o without family history of prostate cancer } \\
\text { and normal digital rectal exams who are ordered PSA test }(n=2726)\end{array}$ & $37.31(1.34)$ & $42.57(2.64)$ & 0.0301 \\
\hline $\begin{array}{l}\% 40 \text { y/o monogamous, female patients with } 2 \text { days of vaginal itching and thick white } \\
\text { discharge without abdominal pain or fever who are required an office visit }(n=2726)\end{array}$ & $21.84(0.95)$ & $34.91(2.61)$ & $<0.001$ \\
\hline $\begin{array}{l}\% 10 \text { y/o males with primary enuresis with negative work-up and failure of water restriction } \\
\text { and environmental measures who are prescribed } \operatorname{DDAVP}(n=2726)\end{array}$ & $26.23(0.84)$ & $31.98(2.50)$ & 0.0265 \\
\hline $\begin{array}{l}\% 10 \text { y/o males with } 2 \text { day history of sore throat and fever who required an office visit }(n= \\
2726)\end{array}$ & $31.74(1.03)$ & $25.92(1.99)$ & 0.0084 \\
\hline $\begin{array}{l}\% 10 \text { y/o females with fever, tachypnea and right-basilar rales who are ordered chest } X \text {-rays } \\
(n=2726)\end{array}$ & $23.40(1.01)$ & $27.56(2.22)$ & 0.0574 \\
\hline $\begin{array}{l}\text { \% 24-month-old females with history of } 6 \text { resolved episodes of supporative otitis media in } \\
\text { past year with normal hearing and failure of prophylactic antibiotics who are referred to ENT } \\
\text { for PE tubes }(n=2726)\end{array}$ & $22.94(0.87)$ & $22.60(1.97)$ & 0.8816 \\
\hline $\begin{array}{l}\text { \% Full-term, 6-week-old children given sepsis work-up (CBC, sterile urine and blood } \\
\text { cultures) for a fever of } 10 \mathrm{I}(\mathrm{n}=2726)\end{array}$ & $29.54(0.91)$ & $26.63(2.25)$ & 0.2458 \\
\hline $\begin{array}{l}\% 4 \text { y/o children with eczema and asthma that is worsening despite inhaled corticosteroids } \\
\text { who are referred to an allergist }(n=2726)\end{array}$ & $29.42(0.97)$ & $28.40(2.3 \mathrm{I})$ & 0.6605 \\
\hline
\end{tabular}

* T-Test

USMG = United States Medical Graduate, IMG = International Medical Graduate, SE = Standard Error

USMGs' board certification status is important, as more emphasis is being placed on this credential. It is also important to address the proposed link between boardcertification status and physician quality in future studies.

\section{Significantly more IMG family physicians are practising in more urban areas as opposed to rural areas}

Previous studies found that IMGs comprise a larger portion of the primary-care physician workforce in rural areas with physician shortages than USMGs, but these studies lumped primary care as a single workforce $[9,10]$. Our study and another national study both reveal that IMGs in family medicine, the primary-care specialty most likely to distribute like the United States population, are less likely to practise in rural areas than USMGs [8].

Although a greater percentage of new physicians entering Health Professional Shortage Areas (HPSAs) are IMGs, the majority of these physicians are temporary visa holders [18]. It is uncertain if this commitment to the underserved is long-term. Furthermore, previous research has revealed that IMGs are more likely to practise in markets with higher concentrations of established IMG physicians [19]. If this trend continues, one may expect IMGs to continue to locate in urban versus rural practices.
The CTS physician survey did not identify HPSAs or visa status, so we were unable to assess the relative placement of IMGs and USMG family physicians in regard to treating the underserved, or their long-term commitment to serving these areas. Additionally, the CTS data do not allow us to perform a more refined analysis of exactly where in urban areas these physicians are located, as other studies looking at IMGs of all specialties have done $[7,20]$.

\section{More IMG practices are open to all new Medicaid and Medicare patients, and a greater percentage of their revenue is derived from these patients}

This trend has also been established in comparing IMGs and USMGs in psychiatry [21]. The greater service of Medicare and Medicaid populations by IMG family physicians suggests they have a greater dependence on publicly financed programmes and that they plan an important role in providing access to care for Americans covered by these federal programmes.

\section{More IMGs are dissatisfied with their overall medical careers}

Previous studies have linked career dissatisfaction with a perceived inability to provide high-quality care [15]. Although more IMGs in this study are dissatisfied than USMGs, they report no less ability to deliver high-quality care to their patients. Furthermore, more IMGs report hav- 
ing adequate time and ability to develop continuing relationships with their patients than their USMG colleagues. Given the link between career satisfaction and quality of care, it is important to consider what potentially increasing the percentage of dissatisfied physicians means for the future of family medicine and the patients they serve. While it is beyond the scope of this study, it is important to further examine this difference in order to discern potential etiologies and solutions to improve physician satisfaction.

In reviewing the clinical vignettes, we noted several situations in which IMGs order more tests, refer more patients or require more office visits than USMGs. These differences were statistically significant for half of the vignettes, but it is uncertain whether this reflects appropriate care or if the differences were clinically significant. To our knowledge, no research has been published examining the referral patterns and service use practices of IMGs and USMG physicians in the United States. This area deserves further examination, as there may be important health care cost and utilization effects to consider if differences between the groups do exist.

As previously stated, it is important to note that there are no significant differences between IMGs and USMGs regarding their self-rated ability to deliver high quality care to their patients. A greater percentage of IMGs feel that they have adequate time to spend with their patients and that they are able to develop continuing relationships with them.

There are several limitations to our study. The cross-sectional nature of this study precludes our ability to demonstrate causal relationships between variables in addition to the potential for selection effects and the inability to assess possible maturation effects. Reporting error and recall bias are always potentials when examining survey data. Furthermore, the data in this study are subjective reports given by physicians themselves, as opposed to objective practice analyses and clinical outcomes.

We are also unable to differentiate between IMGs who were born in the United States and those who were foreign-born. Since United States-born IMGs and "Fifth Pathway" students account for increasing numbers of PGY-1 family practice residents [3], it would be important to determine whether differences exist between this group and their foreign-born counterparts.

The linkage of general practitioners with family physicians by the CTS may affect some of the results of this paper. Although we know the participants were self-reported family physicians or general practitioners, we do not know the primary focus of their practices (traditional practice, emergency physician, occupational medicine, etc.).

In addition, the clinical vignettes were designed by the CTS and their validity is untested. We include them because they offer a unique viewpoint into clinical decision-making that is often not available in data sources.

Our data were collected in 1996 and 1997. This is the most recent nationally representative data source that oversampled primary-care physicians and examined the specific clinical information we needed, including the clinical vignettes. Although the CTS has collected physician survey data in subsequent years (1998-1999, 20002001), neither of these data sets include the pertinent clinical information provided in the vignettes of the 19961997 data set. In addition, this time frame allows us to obtain a snapshot of family practice physicians at the time when USMG interest in family medicine was peaking and the number of IMGs entering the field was poised to increase, thereby providing a baseline with which to compare more recent studies on this issue.

IMGs were just $13.4 \%$ of the CTS sample - less than their percentage in the overall family medicine workforce. We cannot know whether there was a disproportionately lower response rate from IMGs or if IMGs were a smaller proportion of the workforce within the sampled areas. While this may affect external validity, we don't anticipate that non-respondent IMGs would be more satisfied, or less likely to serve Medicare and Medicaid patients. The characteristics reported in this study may have changed over the past nine years.

\section{Conclusion}

At a time when family medicine began a new trend of becoming more populated with IMGs, we found important differences between the professional and clinical attributes and attitudes of IMG and USMG family physicians that may affect the health care system. Unlike previous studies, the practice locations of the IMG family physicians in this study were more urban than those of their USMG peers. IMG family physicians tend to own their practices more often, practise in smaller groups and be more open to serving Medicare and Medicaid patients than their United States-trained colleagues. The lower rate of board certification among IMG physicians is important to consider as more emphasis is being placed on this credential. There were small but significant differences in career satisfaction and referral patterns that are worth exploring both to understand whether they continue to be true, and to understand if they may change the scope and practice of family medicine. Given that the United States relies on family physicians to serve a large portion of its population and the persistent lack of interest in family 
medicine by United States medical students, we need to further understand these differences and how they relate to the health care system as a whole.

\section{Competing interests}

This study was funded by the Robert Graham Center. The information and opinions contained in research from the Graham Center do not necessarily reflect the views or policies of the AAFP. The authors declare they have no competing interests.

\section{Authors' contributions}

ALM participated in study design, data collection and manuscript development and revision. RLP participated in study design and manuscript development and revision. FM participated in critical revision of the manuscript. LAG participated in study design and manuscript development and revision. GEF participated in study design and data collection and performed the statistical analysis. All authors read and approved the final manuscript.

\section{Acknowledgements}

The authors would like to thank Jessica McCann for her assistance with data collection and analysis.

\section{References}

I. Pasko T, Smart DR: AMA Physician Characteristics and Distributions in the US. Chicago: American Medical Association; 2005.

2. Koehn NN, Fryer GE, Phillips RL, Miller JB, Green LA: The increase in international medical graduates in family practice residency programmes. Fam Med 2002, 34(6):429-435.

3. Pugno PA, McPherson DS, Schmittling G, Fetter GT, Kahn NB: Results of the 2005 National Resident Matching Program: Family Practice. Fam Med 2005, 37(8):555-564.

4. Brotherton SE, Rockey PH, Etzel SI: US graduate medical education, 2002-2003. JAMA 290(9): I 197-1202. 2003, Sept 3

5. Whitcomb ME, Miller RS: Comparison of IMG-dependent and non-IMG dependent residencies in the National Resident Matching Program. JAMA 276(9):700-703. 1996 Sept 4

6. Task Force I Writing Group: Task Force I: Report of the Task Force on patient education, core values, reintegration, and the new model of family medicine. AnnFamMed 2004, 2(suppl I):S33-S50.

7. Mick SS, Lee SD, Wodchis WP: Variations in geographical distribution of foreign and domestically trained physicians in the United States: 'safety nets' or 'surplus exacerbation'? Social Science \& Medicine 2000, 50: 185-202.

8. Fink KS, Phillips RL, Fryer GE, Koehn N: International medical graduates and the primary care workforce for rural underserved areas. Health Affairs 2003, 22(2):255-262.

9. Mueller KJ, (University of Nebraska Medical Center, Omaha, NE): The Immediate and Future Role of the J-I Visa Waiver Program for Physicians: The Consequences of Change for Rural Health Care Service Delivery. Final Report Omaha, NE: Rural Policy Research Institute Center for Rural Health Policy Analysis; 2002. Report No: P2002-3

10. Baer LD, Ricketts TC, Konrad TR, Mick SS: Do international medical graduates reduce rural physician shortages? Med Care 1998, 36(II): 1534-1544.

II. Blonski J, Rahm S: The relationship of residency performance to match status and us versus international graduate status. Fam Med 2003, 35(2): 100-104.

12. Mick SS, Comfort ME: The quality of care of international medical graduates: How does it compare to that of U.S. medical graduates? Medical Care Research and Review 1997, 54(4):379-4I3.

13. Lee SD, Dow WH, Wang V, VanGeest JB: Use of deceptive tactics in physician practices: Are there differences between inter- national and US medical graduates? Health Policy 2004, 67:257-264.

14. HSChange.org [home page on the Internet] [http:// www.hschange.org/index.cgi?data=0I]. Washington DC: Center for Studying Health System Change Updated I/I2/2005; Cited January 20, 2005

15. DeVoe J, Fryer GE, Hargraves L, Phillips RL, Green LA: Does career dissatisfaction affect the ability of family physicians to deliver high-quality patient care? J Fam Pract 2002, 5 I(3):223-228.

16. Whelan GP, Gary NE, Kostis J, Boulet JR, Hallock JA: The changing pool of international medical graduates seeking certification training in us graduate medical education programs. JAMA 288(9): 1079-1084. 2002, Sept 4

17. Brennan TA, Horwitz RI, Duffy FD, Cassel CK, Goode LD, Lipner RS: The role of physician specialty board certification status in the quality movement. JAMA 292(9): 1038-1043. 2004, Sept I

18. Salsberg E, Nolan J: The posttraining plans of international medical graduates and US medical graduates in New York State. JAMA 283(13): 1749-1750. 2000, Apr 5

19. Wozniak GD: Policy research perspectives: practice location choices of new international medical graduates. 2002 [http:// www.ama-assn.org/amal/pub/upload/mm/363/ intl medicl grads 02.pdf]. Center for Health Policy Research, American Medical Association Accessed 3I May 2004

20. Mick SS, Lee SD: International and US medical graduates in US cities. Journal of Urban Health 1999, 76(4):48I-496.

21. Blanco C, Carvalho C, Olfson M, Finnerty M, Pincus HA: Practice patterns of international and U.S. medical graduate psychiatrists. Am J Psychiatry 1999, I 56(3):445-450.
Publish with BioMed Central and every scientist can read your work free of charge

"BioMed Central will be the most significant development for disseminating the results of biomedical research in our lifetime. "

Sir Paul Nurse, Cancer Research UK

Your research papers will be:

- available free of charge to the entire biomedical community

- peer reviewed and published immediately upon acceptance

- cited in PubMed and archived on PubMed Central

- yours - you keep the copyright

Submit your manuscript here:

http://www.biomedcentral.com/info/publishing_adv.asp
BioMedcentral 